\title{
Large-Scale Investment in Science: Economic Impact and Social Justice
}

\author{
Massimo Florio
}

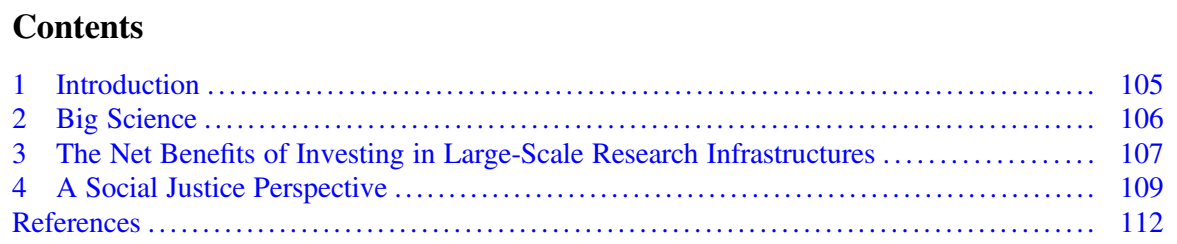

\section{Introduction}

Science is not a free lunch. Worldwide, R\&D expenditures per year, from basic research to product development by firms, are about USD1.7 trillion (according to UNESCO estimates for 2017). There are perhaps 7.8 million professional researchers globally, around one researcher out of one thousand inhabitants of the planet. In the OECD area, which includes the most developed economies, government R\&D spending is worth about USD 315 billion per year and the share of government of the total $R \& D$ expenditures is $28 \%$. Hence, citizens support research in two ways: firstly, as consumers by paying a price for goods and services which in turn include in their production costs such expenditures; secondly, by paying taxes which support government R\&D expenditures, mostly for basic science.

In this short essay, I discuss two questions: What is the economic impact of basic research? What are the implications for social justice of the interplay between -on one side- government funded science and -on the other side- R\&D supported by business? I will argue that the ultimate economic impact of large-scale investment in basic research is often (but not always) positive (i.e. benefits are greater than costs).

\footnotetext{
M. Florio $(\bowtie)$

Department of Economics, Management, and Quantitative Methods, University of Milan, Milan, Italy

e-mail: massimo.florio@unimi.it 
There is, however, a potential concern for social justice arising from the private appropriation by business of rents arising from knowledge as a public good.

\section{Big Science}

The main paradigm of knowledge creation for centuries has been based on small scale organizations. Galileo or Newton did not manage large laboratories, and still today there is a considerable role for Little Science: a principal investigator with a small team of postdocs and $\mathrm{PhD}$ students. An entirely different organization model has emerged particularly during World War II. The most famous example is the Manhattan Project in the US, that involved thousands of the best physicists and engineers to design and build the first atomic bomb. Another example of this Big Science model is the Apollo Lunar Program, that wanted at the same time to put one man on the Moon, and show to the world that the Cold War could not have been won by the USSR in terms of technological superiority.

There are many other examples: the Nazi atomic bomb program with the involvement of Heisenberg, the French dual nuclear program with both civilian and military missions, the many Soviet 'closed cities' employing tens of thousands of scientists including Nobel laureates, the British secret computer science with Turing, etc.

The main features of the traditional Big Science model are its national scope and defense-related mission, hence a close relation with the military-industrial complex, secrecy, political loyalty of the personnel, top up governance. My claim is that from post-WWII Europe a completely different Big Science model emerged, and CERN is the most important example of it: a large-scale research infrastructure entirely driven by curiosity of a scientific community and explicitly rejecting any connection with the military, based on an international coalition without a main 'owner', adopting open-science style and bottom-up governance. Another example of the new paradigm is the Human Genome Project (1990-2003). The HGP was initially funded by the US Department of Energy (which inherited the Manhattan Project facilities and the study of radioactivity genetic effects), by the US National Institutes of Health, but then involving an international coalition of researchers. In fields as diverse as astronomy, space exploration, materials science, marine biology, and large-scale clinical trials the new research infrastructure (RI) paradigm has successfully changed the landscape of science. Even the contemporary Little Science in fact benefits from access to open data created and distributed by the large RIs, with the crucial possibilities offered by the internet and the World Wide Web (both inventions arising from government funded science, respectively in the US ARPANET agency, and at CERN). The European Bio-Informatics Institute, part of the European Molecular Biology Laboratory (EMBL), a repository of bio-data, is accessed for free every day 70 million times by more than three million unique IP. A PhD student may believe that she is working somewhere in a small laboratory, but in fact she is connected with a global virtual community sharing data, software, and online resources in general. 
There is a fundamental difference between the old and the new Big Science paradigm in terms of the opportunity of evaluating their socio-economic impact. Several benefits are similar, for example in the perspective of the economic value of technological progress, but the old Big Science is loaded by military missions which create untreatable problems for social cost-benefit analysis. In fact, there is no sensible way to compare in a global perspective the economic benefits of the Manhattan Project for the US (around 130,000 employees and thousands of companies involved as contractors and suppliers) with the socio-economic effects for Japan of the destruction of Hiroshima and Nagasaki. Apart from any ethical considerations, no cost-benefit analysis of public investment in defense is possible because we do not know how to consider the economic value of war destruction.

When there are no direct military missions, RIs can be evaluated in cost-benefit analysis terms just assuming that the pure knowledge they create will not be harmful. This seemingly modest but crucial assumption paves the way to measurement of RIs' benefits and costs for society using the tools of applied welfare economics. I turn now on this approach.

\section{The Net Benefits of Investing in Large-Scale Research Infrastructures}

Large-scale investment projects in science are costly. A last generation synchrotron light source has an investment cost of some USD 100 million, and gravitational waves, radio-astronomy, particle physics, nuclear fusion, spallation neutron sources, but also population genomics, or new cancer drugs may require RI budgets in the billion USD scale. In the last 6 years, an interdisciplinary team of the University of Milan and of the Centre for Industrial Studies (CSIL Milano), including economists, statisticians, computer scientists and physicists (particularly Professor Stefano Forte of the UNIMI Department of Physics), has carefully studied the balance of measurable social benefits and costs of the Large Hadron Collider, and the CNAO synchrotron for hadron therapy. The study has been further extended to synchrotron light sources (such as ALBA), distributed RIs for heritage sciences, satellites for Earth Observation, and procurement of the space agencies (particularly of ASI, the Italian Space Agency).

On the cost side, a CSIL team has very recently (2019) provided detailed costing guidelines for the new ESFRI Roadmap (the European Strategy Forum for Research Infrastructures). On the benefits side, in order to avoid double counting and inconsistencies in measurement, our team has suggested a simple intertemporal model of impacts on different social groups: scientists, students and early career researchers, firms involved in procurement, users of products and services embodying technological innovations, users of cultural goods, and finally 'non-users': the general public that includes the taxpayers funding the RIs. The details are explained in Florio [1]. 
Both costs and benefits must be expressed in a common numeraire, such as Euros or any other currency. In applied welfare economics this is just a measurement convention and does not mean that all the costs (including pollution or traffic congestion) and all the benefits (including visiting an exhibition or a website) actually generate cash transactions. It only means that measurement can be done by an appropriate metric. For example, units of time would also work in principle, and in such case one may estimate whether project costs expressed in time units of standard human effort are greater or smaller than social benefits expressed also in such time units (to see the equivalence just consider that the marginal social value of time is related to what one could earn in money terms even if she doesn't work at all).

The surprising result of the social Cost Benefit Analysis (CBA) of the LHC to 2025 is that the 'side' benefits of the LHC are conservatively estimated to be in excess of its costs with a ratio 1.20; i.e. one Euro of costs returns to society 1.20 benefits. This holds true without considering the unknown value of discovering the Higgs boson or of any other past and future discoveries of the collider (just assuming that such knowledge does no harm). In a new study of the future High-Energy Large Hadron Collider the benefit/cost ratio has been estimated to be 1.8, even greater than the LHC's one [2].

One third of these benefits arise from technological learning for firms involved in the supply chain [3]. These firms, particularly the hi-tech ones, have tested at the LHC new cutting edge technologies, sometimes developed in close contact with scientists and engineers at CERN or in the Collaborations. As a result, firms can take advantage of such knowledge. In economic terms this is an externality and our team has measured very carefully with different econometric methods its impact in terms of additional $\mathrm{R} \& \mathrm{D}$, patents, productivity, sales, and ultimately profits for CERN suppliers [4].

Another third of the benefits is related to human capital increase for students and early career researchers involved in CERN projects and Collaborations. This is a lifelong effect of skills acquired in a unique scientific and technological environment which translates in a salary premium that we have estimated with different statistical methods based on interviews to current students at CERN, former students now employed elsewhere, and University team leaders. We have also looked at the structure of premium salaries for physicists with different backgrounds (for example with or without specific data analytics skills) [5]. A minor effect for insiders is also related to the narrowly defined value of publications and their influence in the literature, considered just as a product of time and effort (as mentioned without trying to estimate the completely uncertain future economic value of the knowledge embodied in a publication).

Finally, another third of the socio-economic benefits of the LHC arises from use and non-use benefits for the public. The former is related to the implicit willingness to pay for visiting CERN (no admission ticket but there are travel and other costs which point to a value of such visits) or for using cultural products such as websites, traveling exhibitions etc. The latter is the hidden willingness to pay by taxpayers, who de facto fund the LHC. But are they really willing to pay for it? 
Two very recent contingent valuation experiments with surveys targeting representative samples of French and Swiss taxpayers respectively, have revealed an estimate of the willingness to pay (WTP) for research in particle physics for the first time worldwide. The surveys were designed and implemented in conformity with the most rigorous standards for such experiments and approved by the Ethics Committee of the University of Milan. In both countries the average respondent, after having inspected some information provided by CERN, has declared her WTP in the form of a tax increase for future investment at CERN. The result is positive and in fact greater than the current implicit tax paid. In France, while around 49 percent of the respondents have WTP $=0$ (usually the less educated, low income, and old people), in fact a thin majority of the respondents have a WTP $>0$.The overall average is around 4 Euro per year per person, against an actual tax burden around 2.7 Euro. In Switzerland the results are even more positive (with a much lower share of respondents with WTP $=0$ and a higher positive WTP), and converging to a much greater value than current tax burden for both a subsample not informed and one informed (during the interview) about how much their taxes pay for CERN [6].

Obviously, the main argument for taking a decision about a large-scale RI must be its scientific case, and one may think solid scientific cases for a RI were measurable social costs - to the best of our knowledge-exceed the predictable benefits. Interestingly, one may also think that to projects where the scientific case is not very strong (perhaps e.g. exploration of Mars with a human mission versus using robots) but the side benefits (for example those related to cultural goods) are strong, a feature well known to NASA managers. It seems in any case that some social cost-benefit analysis is informative as a complement to the scientific cases in order to see a more complete scenario.

While cost-benefit analysis may be able to answer the question of measurable net social benefits at the aggregate level, one may ask a further question: in a planet where inequality and other urgent societal challenges are of major concern, is costly investment in basic science a priority?

\section{A Social Justice Perspective}

To answer the question one needs to clarify its meaning. There are two different aspects. The first one is whether public money spent in detecting the gravitational waves, the Higgs boson, or other apparently 'un-useful' science should be better spent, for example, for research on cancer or on climate change, or even to immediately provide health care and food for the poor. The second issue is whether the social benefits of investment in science are fairly distributed in terms of equity.

It is important to acknowledge that these are two different questions, and one should not confuse them. The answer to the first question is intrinsically a matter of policy priorities, and there is no serious answer in the perspective of applied welfare economics. One may use the rhetorical argument that science will always produce a benefit for everybody. Looking backwards there may be many good examples. 
Scientists do love this argument, particularly when the conversation is about their own project (less so when it is about a rival project or about another field). Unfortunately, the argument is a pretty unscientific one. Clearly, it is not an argument for spending whatever amount of taxpayers' money in whatever research field and forever. Resources in terms of money, personnel, time, energy and materials are not infinite at any given moment. Thus, spending priorities are needed. One may say that building a future particle collider is not a priority, but also one could say that investing in a modern air-carrier of the US or French Navy, which costs several times a LHC, should be delayed until more urgent needs are satisfied. By extension, the same reasoning could apply, however, to most public and private spending as well. This argument hence leads to nowhere. Decision-making on policy priorities and on individual preferences cannot be based on strict social cost-benefit considerations, mainly because of heterogeneity of preferences of individuals and because of radical uncertainty about certain aspects of the distant future. Both economists and scientists should acknowledge that setting policy priorities is part of a political process. One may have opinions about preferred decisions, but it would be difficult to empirically prove how much should be spent by governments in basic science to maximize long-term socio economic benefits. As I mentioned in the Introduction, government funding in the R\&D in the OECD area is in the region of USD250 per capita per year. Establishing if it should instead be USD150 or USD350 is an interesting but probably not a better question than the never- ending discussion about how much should be the optimal spending in defense, public universities, health care, or on supporting the fine arts, just to mention some examples.

Having said this, I claim that the different question about the fairness of the current arrangements for government support to science can be investigated in welfare economics terms and in fact may lead to some surprising issues.

Let us consider some examples in biomedical sciences. The Human Genome project had a cumulated cost of around USD3 billion over 12 years entirely supported by taxpayers. It has created new knowledge: we now know that there are around 3 billion base pairs in our genome (by chance the research cost was one dollar per base), and we also know that there are something like 20,000 proteinencoding genes and many more non- protein- encoding ones. Moreover, the knowledge creation process was highly dynamic, new technologies emerged that now allow to analyze a whole human genome at less than one thousand USD and in just $1 \mathrm{~h}$. Databases with millions of such sequenced genomes will be created in the next few years and medicine will be deeply influenced by such knowledge. A social justice issue here arises from the tension between the public good nature of government supported science and the private appropriation of economic benefits.

The HGP data were disseminated according to a form of open science model (the Bermuda conference declaration). In 2013 the US Supreme Court ruled that human genes cannot be patented. However, several hundreds of new biotech products and several thousand patents were derived by the HGP knowledge. Huge capital gains and profits were created in the health industry after the most risky and long-term basic research was paid by the taxpayers. Taxation of capital income is notoriously lower than taxation of labor everywhere in the world, and one may easily see that 
there has been a transfer of wealth from the average taxpayer to the average investor in the biotech industry, who de facto enjoyed a considerable discount on R\&D investment costs. In a counterfactual scenario, one may have designed more effective ways to defend the public good nature of knowledge of the human genome. A perhaps even more revealing case, of a different nature, is the role played for R\&D on drugs by the National Institutes of Health (which is worldwide the most important RI -or set of RIs- for biomedical sciences). According to a recent study [7], the R\&D of all 210 drugs later approved in the US received NIH funds at the average level of USD840 million per each new drug (and some of such drugs have been supported also by other funding agencies as well). Statistics on internal $R \& D$ by private companies is opaque to say the least. Some studies claim that they need to spend USD1.4 billion on R\&D per each drug of their own funds. Other studies [8] suggest, however, that this figure is exaggerated for regulatory reasons, and the true value could be around USD648 million for each recent cancer drug. In any case, these estimates of R\&D spending by firms imply that the government is a de facto a major funding partner for pharma companies with a $45-55 \%$ share of R\&D. Compounded with the extremely high prices of new drugs, this leads to high margins of the pharmaceutical industry (after-tax margins around 24\% after capitalizing R\&D and leases, according to Prof. A. Damodoran of New York University, cited by [9]). It is apparent that citizens are paying twice the bill: firstly, as taxpayers supporting the riskiest part of the research, later as patients directly or indirectly paying the price of drugs. Moreover, patients also donate their data to firms supporting large scale clinical trials. These two examples of asymmetric effects of government funding of science are part of a much wider panorama. As mentioned, CERN has been instrumental to many innovations, including the World Wide Web, and ARPANET to the internet. A large part of the innovations related to computer science and the digital economy can be traced back to government supported research [10]. But it is also apparent that a considerable component of social inequality of our days is related to the fact that investors in the big digital knowledge-based companies (now ranked top of the world by market value) have accumulated huge wealth because they have been able to privately appropriate the economic benefits of scientific and technological knowledge released for free by government- funded research institutions.

There is a paradox in the current research infrastructure model: the more it creates path-breaking knowledge as a public good with the support of taxpayers, the more monopolistic or oligopolistic private companies are able to prosper and extract rents from consumers. Modern big science critically contributes to economic growth and prosperity, but we need to think again how government funded research can contribute to social justice as well. 


\section{References}

1. Florio M. (2019). Investing in Science. Social Cost-Benefit Analysis of Research Infrastructures. The MIT Press.

2. Bastianin A., and Florio M. (2018). Social Cost-Benefit Analysis of HL-LHC. https://cds.cern. ch/record/2319300/files/CERN-ACC-2018-0014.pdf

3. Castelnovo P., Florio M., Forte S., Rossi L., and Sirtori E. (2018). "The economic impact of technological procurement for large-scale research infrastructures: Evidence from the Large Hadron Collider at CERN." Research Policy, 47(9), 1853-1867.

4. Florio M., Giffoni F., Giunta A., and Sirtori E. (2018). "Big science, learning, and innovation: evidence from CERN procurement". Industrial and Corporate Change, 27(5), 915-936.

5. Camporesi T., Catalano G., Florio M., and Giffoni F. (2017). "Experiential learning in high energy physics: a survey of students at the LHC." European Journal of Physics, 38(2), 025703

6. Florio M., and Giffoni F. (2018). Scientific Research at CERN as a Public Good: A Survey to French Citizens. http://cds.cern.ch/record/2635861/files/CERN-ACC-2018-0024.pdf

7. Cleary E. G., Beierlein J. M., Khanuja N. S., McNamee L. M., and Ledley F. D. (2018). "Contribution of NIH funding to new drug approvals 2010-2016." Proceedings of the National Academy of Sciences, 115(10), 2329-2334.

8. Prasad V., and Mailankody S. (2017). "Research and Development Spending to Bring a Single Cancer Drug to Market and Revenues after Approval” JAMA internal medicine, 177(11), 15691575.

9. The Economist (2019). "Pharmaceuticals. Profit warning", June 22, 53.

10. Mazzucato M. (2015). The Entrepreneurial State: Debunking Public vs. Private Sector Myths. Anthem Press.

Open Access This chapter is licensed under the terms of the Creative Commons Attribution 4.0 International License (http://creativecommons.org/licenses/by/4.0/), which permits use, sharing, adaptation, distribution and reproduction in any medium or format, as long as you give appropriate credit to the original author(s) and the source, provide a link to the Creative Commons licence and indicate if changes were made.

The images or other third party material in this chapter are included in the chapter's Creative Commons licence, unless indicated otherwise in a credit line to the material. If material is not included in the chapter's Creative Commons licence and your intended use is not permitted by statutory regulation or exceeds the permitted use, you will need to obtain permission directly from the copyright holder.

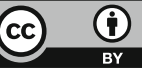

